\title{
PVA/Polysaccharides Blended Films: Mechanical Properties
}

\author{
Fábio E. F. Silva, Maria Carolina B. Di-Medeiros, Karla A. Batista, and Kátia F. Fernandes \\ Laboratório de Química de Proteínas, Departamento de Bioquímica e Biologia Molecular, ICB 2, Universidade Federal de Goiás, \\ Caxia Postal 131, 74001-970 Goiânia, GO, Brazil \\ Correspondence should be addressed to Kátia F. Fernandes; katia@icb.ufg.br
}

Received 30 November 2012; Revised 1 March 2013; Accepted 8 March 2013

Academic Editor: Peter Chang

Copyright (c) 2013 Fábio E. F. Silva et al. This is an open access article distributed under the Creative Commons Attribution License, which permits unrestricted use, distribution, and reproduction in any medium, provided the original work is properly cited.

\begin{abstract}
Blends of polyvinyl alcohol (PVA) and angico gum (AG) and/or cashew gum (CG) were used to produce films by casting method. Morphological and mechanical properties of these films were studied and compared to the properties of a commercial collagen membrane of bovine origin (MBO). The films presented thickness varying from 70 to $140 \mu \mathrm{m}$ (PVA/AG) and 140 to $200 \mu \mathrm{m}$ (PVA/CG). Macroscopic analysis showed that a PVA/CG film was very similar to MBO regarding the color and transparency.

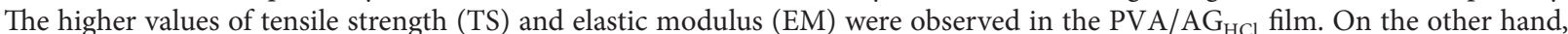
PVA/CG and PVA/CG-AG presented the highest value of percentage of elongation (E\%). Pearson's Correlation Analysis revealed a positive correlation $(r=0.83)$ between TS and EM and a negative correlation $(r=-0.79)$ between $E \%$ and EM. The PVA/CG film presented mechanical properties very similar to $\mathrm{MBO}$, with the advantage of a higher $E \%$ (11.96) than $\mathrm{MBO}$ (2.94). The properties of the PVA blended films depended on the polysaccharide added in the blend, as well as the acid used as a catalyst. However, all produced films presented interesting mechanical characteristics which enables several biotechnological applications.
\end{abstract}

\section{Introduction}

There has been an expanding search for new materials with high performance at affordable costs in recent years [1]. Particularly important are the efforts to develop new materials with film-forming capacity for biomedical applications. Materials for biomedical applications or biomaterials have been defined as those intended to interface with biological systems to evaluate, treat, augment, or replace any tissue, organ, or function of the body [2]. Currently, bioresorbable and biodegradable membranes have been highlighted in the medical market, owing to their inherent biocompatibility $[2,3]$.

Polyvinyl alcohol (PVA) has excellent film-forming properties and has been frequently blended with synthetic and natural polymers due to its water-soluble, biodegradable, innocuous, noncarcinogenic, and biocompatible character $[4,5]$. Blended materials assemble the properties of each material on its own. In general, blended materials are made of a material that acts as a matrix, while the other is imbedded in the matrix material improving its mechanical and physical properties. In this sense, the final properties of the blended material depend on the properties of the imbedded material [6].

In this scenario, blends of proteins or polysaccharides with polyvinyl alcohol (PVA) are promising biodegradable materials since the combination of these polymers may have beneficial effects on the characteristics of the blended material. However, the use of animal proteins in the formulation of biological membranes requires a highly purified material to avoid allergic reactions and increased inflammatory response. The laborious and time-consuming techniques of protein purification result in materials with a high cost.

On the other hand, polysaccharides have been explored as biomaterials, particularly when used as scaffolds for tissue regeneration and controlled drug releasing. Several plants produce gummous exudates mainly composed of high-molecular polysaccharides. Studies of several different gummous materials showed that they consist of complex branched polysaccharides with highly varied chemical and structural composition. Red angico (Anadenanthera macrocarpa) produces gummous exudates composed of arabinose $(67 \%)$, galactose $(24 \%)$, rhamnose $(2 \%)$, and glucuronic acid (7\%) $[7,8]$. Cashew (Anacardium occidentale) also produces 
gummous exudates, constituted of galactose (72-61\%), glucose (14-8\%), arabinose (4.6-14\%), rhamnose (3.2-7\%), and glucuronic acid (4.7-5\%) [9-11]. These gummous exudates are inexpensive, nontoxic, biocompatible, and biodegradable polymers with good rheological properties. These factors enable their use for biodegradable membrane fabrication $[7,9]$.

In this research, biodegradable films were manufactured by blending cashew gum and/or angico gum with PVA. The blended films were characterized according to their morphology and mechanical properties. Additionally, in order to evaluate the potential of these blended films, their properties were compared with those presented by a commercially available biomembrane containing collagen (bovine origin).

\section{Material and Methods}

2.1. Materials. Samples of the cashew exudates (nodules) (Anacardium ocidentale) were collected at CIALNE (Companhia de Alimentos do Nordeste) farm, Pacajus, CE, Brazil. Samples of the angico exudates (nodules) (Anadenanthera macrocarpa) were collected at Anápolis-GO, Brazil. The commercial membrane of bovine origin (MBO) used in this work was purchased from GenDerm (Baumer, Brazil).

2.2. Origin and Purification of Polysaccharides. The gum from cashew exudates was extracted according to the methodology described by Silva et al. [9]. Briefly, the nodules were milled, immersed in distilled water in a proportion of $20 \%(\mathrm{w} / \mathrm{v})$, and kept at room temperature $\left(25^{\circ} \mathrm{C}\right)$, for 24 hours. The solution was filtered to remove fragments of bark and then precipitated with absolute ethanol, in the proportion of $1: 3$ (v/v), for 24 hours. The precipitated cashew gum (CG) was separated by filtration, washed with ethanol, dried at room temperature $\left(25^{\circ} \mathrm{C}\right)$, and stored at room temperature in hermetically closed vessels.

The gums from angico exudates were milled, immersed in distilled water in a proportion of $20 \%$ (w/v), and kept at room temperature $\left(25^{\circ} \mathrm{C}\right)$, for 24 hours. The solution was filtered to remove fragments of bark and then precipitated with absolute ethanol, in the proportion of $1: 3(\mathrm{v} / \mathrm{v})$, for 24 hours. Alternatively, after filtration, the angico gum solution was acidified to $\mathrm{pH} 4.0$ with acetic acid followed by precipitation with cold ethanol. The precipitated angico gum (AG or $A_{a c}$ ) was separated by filtration, washed with ethanol, dried at room temperature $\left(25^{\circ} \mathrm{C}\right)$, and stored at room temperature in hermetically closed vessels.

2.3. The Preparation of the Films. In order to obtain a film with mechanical properties similar to the commercial MBO, several formulations were tested using cashew gum (CG), angico gum (AG), or a mixture of cashew and angico gum.

The PVA/CG film was prepared by casting on the glass molds a solution containing a mixture of $7.5 \mathrm{~mL}$ of $3 \%(\mathrm{w} / \mathrm{v})$ acidic PVA solution ( $\mathrm{pH} 2.0$ ), $7.5 \mathrm{~mL}$ of $3 \%(\mathrm{w} / \mathrm{v})$ cashew gum aqueous solutions, $0.75 \mathrm{~mL}$ of $0.1 \mathrm{~mol} \mathrm{~L}^{-1}$ sodium metaperiodate as a cross-linker, and $0.75 \mathrm{~mL}$ of $0.1 \mathrm{~mol} \mathrm{~L}^{-1}$ sulfuric acid as catalyst. The solvent evaporation was left to occur at room temperature $\left(25^{\circ} \mathrm{C}\right)$ for 24 hours. The dry films were stored in plastic bags before all subsequent characterization procedures.

The PVA/AG films were prepared by casting on the glass molds a solution containing a mixture of $7.5 \mathrm{~mL}$ of $3 \%(\mathrm{w} / \mathrm{v})$ acidic PVA solution ( $\mathrm{pH} 2.0), 7.5 \mathrm{~mL}$ of $3 \%(\mathrm{w} / \mathrm{v})$ angico gum aqueous solutions, $0.75 \mathrm{~mL}$ of $0.1 \mathrm{~mol} \mathrm{~L}^{-1}$ sodium metaperiodate as a cross-linker, and $0.75 \mathrm{~mL}$ of $0.1 \mathrm{~mol} \mathrm{~L}^{-1}$ phosphoric acid $\left(\mathrm{PVA} / \mathrm{AG}_{\mathrm{PO}_{4}}\right.$ ) or $0.1 \mathrm{~mol} \mathrm{~L}{ }^{-1}$ hydrochloric acid $\left(\mathrm{PVA} / \mathrm{AG}_{\mathrm{HCl}}\right.$ ) as a catalyst. The $\mathrm{PVA} / \mathrm{AG}_{\mathrm{ac}}$ film was prepared by casting on the glass molds a solution containing a mixture of $7.5 \mathrm{~mL}$ of $3 \%(\mathrm{w} / \mathrm{v})$ acidic PVA solution ( $\mathrm{pH} 2.0)$, $7.5 \mathrm{~mL}$ of $3 \%(\mathrm{w} / \mathrm{v}) \mathrm{AG}_{\mathrm{ac}}$ aqueous solution, $0.75 \mathrm{~mL}$ of $0.1 \mathrm{~mol}$ $\mathrm{L}^{-1}$ sodium metaperiodate as a cross-linker, and $0.75 \mathrm{~mL}$ of $0.1 \mathrm{~mol} \mathrm{~L}^{-1}$ sulfuric acid as a catalyst. The solvent evaporation was left to occur at room temperature $\left(25^{\circ} \mathrm{C}\right)$ for 24 hours. The dry films were stored in plastic bags before all subsequent characterization procedures.

The PVA/CG-AG film was prepared by casting on the glass molds a solution containing a mixture of $7.5 \mathrm{~mL}$ of $3 \%(\mathrm{w} / \mathrm{v})$ acidic PVA solution ( $\mathrm{pH} 2.0), 3.25 \mathrm{~mL}$ of $3 \%$ $(\mathrm{w} / \mathrm{v})$ cashew gum aqueous solutions, $3.25 \mathrm{~mL}$ of $3 \%(\mathrm{w} / \mathrm{v})$ angico gum aqueous solutions, $0.75 \mathrm{~mL}$ of $0.1 \mathrm{~mol} \mathrm{~L}^{-1}$ sodium metaperiodate as a cross-linker, and $0.75 \mathrm{~mL}$ of $0.1 \mathrm{~mol} \mathrm{~L}^{-1}$ sulfuric acid as catalyst. The solvent evaporation was left to occur at room temperature $\left(25^{\circ} \mathrm{C}\right)$ for 24 hours. The dry films were stored in plastic bags before all subsequent characterization procedures.

\subsection{Film Characterization}

2.4.1. Films Thickness and Morphology. The thickness of the blended films was determined using a manual micrometer (Mitutoyo, São Paulo, Brazil). Final thickness was determined by means of ten random determinations in all film area. The films were analyzed according to morphological overall characteristics such as color, transparency, and homogeneity.

2.4.2. Mechanical Properties. Mechanical properties were determined in an Instron M3345 (Instron Co., Norwood, MA, USA), with a $50 \mathrm{~N}$ load cell equipped with tensile grips. Samples of the film were cut into strips of $10 \mathrm{~mm}$ wide and $30 \mathrm{~mm}$ long, according to the ASTM D-638M-93 standard [12]. The grip separation was set at $10 \mathrm{~mm}$, with a crosshead speed of $5 \mathrm{~mm} \mathrm{~min}^{-1}$. Each sample used was previously inspected and those containing any defect such as air bubbles, holes, and tears or showing average thickness variation superior to $5 \%$ were rejected. All samples were tested with curing time greater than 30 days, in dehydrated state.

Tensile strength (TS), percentage of elongation (E\%) at break, and elastic modulus (EM) were evaluated using the Software Blue Hill 2 (Instron Co.). The percentage of elongation $(E \%)$ at break was calculated as follows:

$$
\text { Elongation }(E \%)=\frac{\left(L_{f}-L_{i}\right) \times 100}{L_{i}},
$$

where $L_{i}$ is the initial length and $L_{f}$ is the final length. 


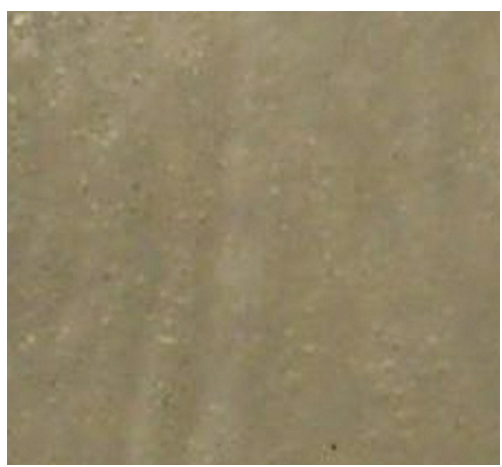

(a)

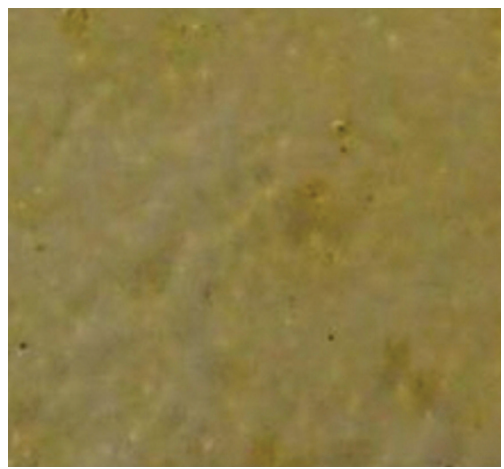

(d)

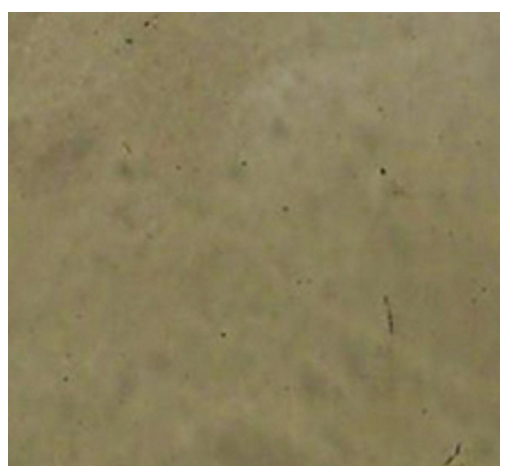

(b)

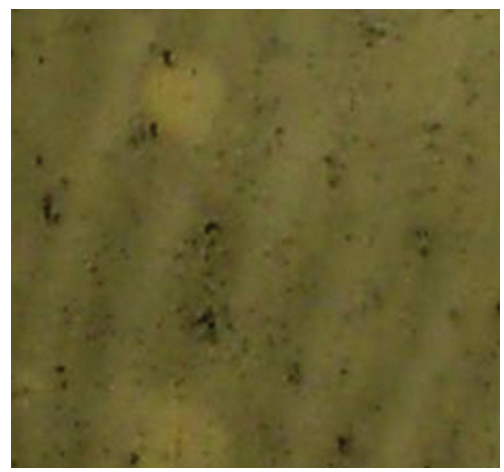

(e)

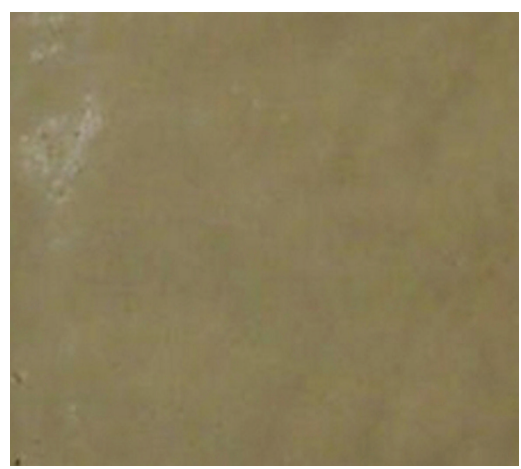

(c)

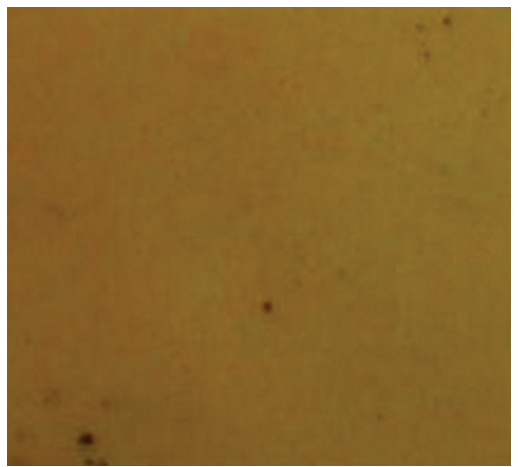

(f)

FIGURe 1: Macroscopic morphology of the films: (a) MBO; (b) PVA/CG film; (c) PVA/CG-AG film; (d) PVA/AG $\mathrm{PO}_{4}$ film; (e) PVA/AG HCl film; and (f) PVA/AG ac film.

The modulus of elasticity (Young's modulus) was determined according to the following equation:

$$
\text { Modulus of elasticity }(Y)=\frac{F L_{i}}{A_{0} \Delta L} \text {, }
$$

where $F$ is the force exerted on an object under tension; $A_{0}$ is the original cross-sectional area through which the force is applied; $\Delta L$ is the amount by which the length of the object changes; and $L_{i}$ is the original length of the object.

2.5. Statistical Analysis. All experiments were expressed as average \pm standard deviation $(X \pm S D)$. The variance analysis and Tukey's test were used to define differences in mean values of the data from 3 to 6 replicates. The variance analyses were carried out using the software Statistica 6.0 (StatSoft, Inc., Tulsa, OK, USA, 1997). The means of the treatment with the same letters are not significantly different $(P \leq 0.05)$.

\section{Results and Discussion}

3.1. Appearance of the Films. The PVA/CG films presented thickness values between 140 to $200 \mu \mathrm{m}$, while PVA/AG films presented thickness around 70 and $140 \mu \mathrm{m}$. Figure 1 shows samples of formulated films and the membrane of bovine origin (MBO). As can be observed, the produced films presented a high diversity of color and transparency. Among
TABLE 1: Mechanical properties of blended films.

\begin{tabular}{lccc}
\hline & $\begin{array}{c}\text { Tensile strength } \\
(\mathrm{kgf})\end{array}$ & $\begin{array}{c}\text { Elongation } \\
(\%)\end{array}$ & $\begin{array}{c}\text { Elastic modulus } \\
(\mathrm{kgf})\end{array}$ \\
\hline $\mathrm{MBO}$ & $193.61^{\mathrm{b}}$ & $2.94^{\mathrm{b}}$ & $6568.14^{\mathrm{b}}$ \\
$\mathrm{PVA} / \mathrm{CG}$ & $151.84^{\mathrm{b}}$ & $11.96^{\mathrm{a}}$ & $1305.25^{\mathrm{c}}$ \\
$\mathrm{PVA} / \mathrm{CG}-\mathrm{AG}$ & $218.17^{\mathrm{b}}$ & $13.24^{\mathrm{a}}$ & $1800.85^{\mathrm{c}}$ \\
$\mathrm{PVA} / \mathrm{AG}_{\mathrm{PO}_{4}}$ & $227.97^{\mathrm{b}}$ & $4.87^{\mathrm{b}}$ & $4773.82^{\mathrm{b}}$ \\
$\mathrm{PVA} / \mathrm{AG}_{\mathrm{HCl}}$ & $426.46^{\mathrm{a}}$ & $3.80^{\mathrm{b}}$ & $11590.02^{\mathrm{a}}$ \\
$\mathrm{PVA}_{\mathrm{AGG}}$ & $221.30^{\mathrm{b}}$ & $3.18^{\mathrm{b}}$ & $6972.95^{\mathrm{b}}$ \\
\hline
\end{tabular}

${ }^{\mathrm{a}}, \mathrm{b}$, and ${ }^{\mathrm{c}}$ : The results are the means of three determinations. Within columns, means with the same superscript letter are not significantly different $(P>0.05)$.

them, the PVA/CG films presented the higher transparency and slightly white color, very similar to MBO.

3.2. Mechanical Properties. Artificial membranes have focus of special attention owing to their potential application in the medical fields, such as drug delivery systems, artificial organs, and tissue engineering [13]. To every application, specific mechanical features are required. In general, the mechanical properties of the films produced by blending PVA with CG were similar to those of the MBO (Table 1), whereas films with AG or $A_{\mathrm{ac}}$ had mechanical properties slightly different. 


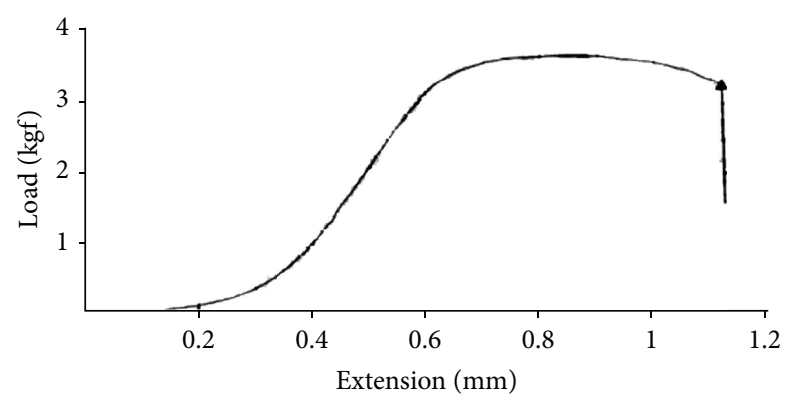

(a)

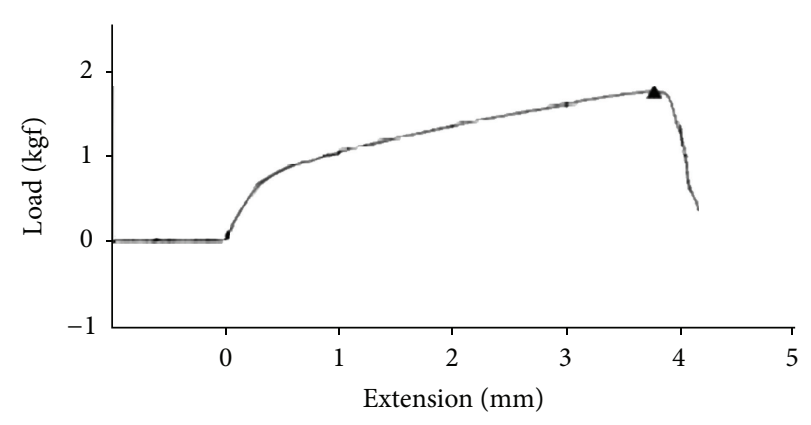

(c)

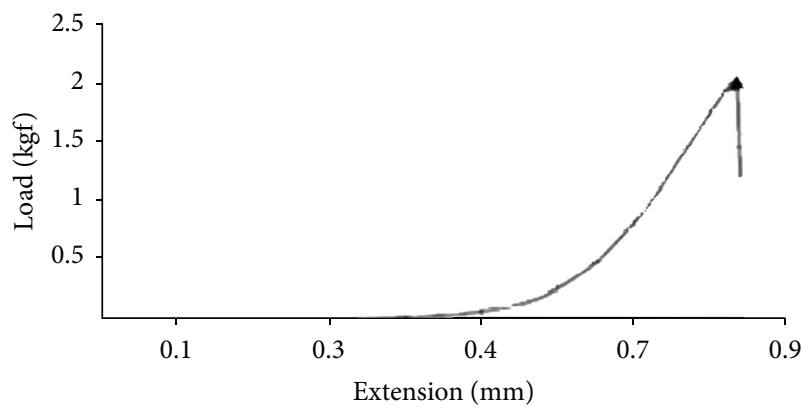

(e)

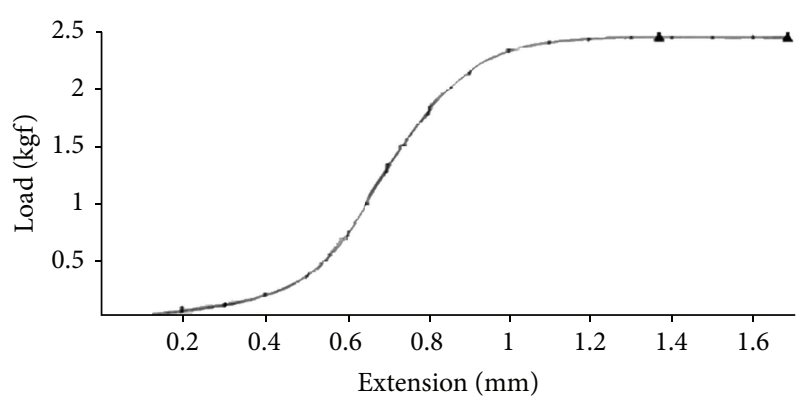

(b)

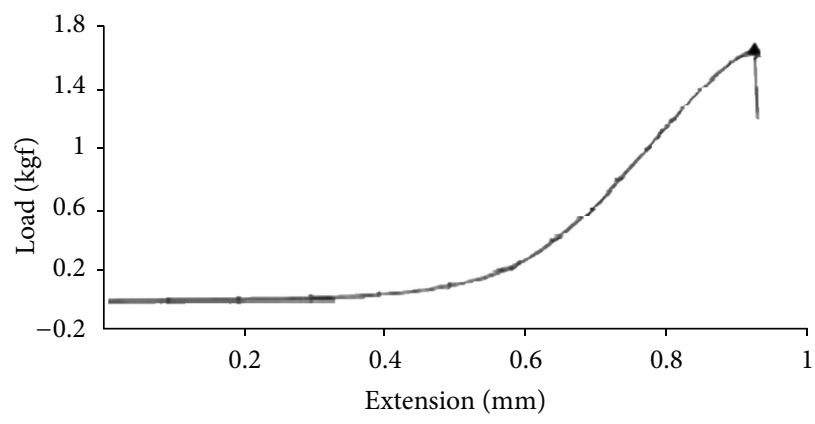

(d)

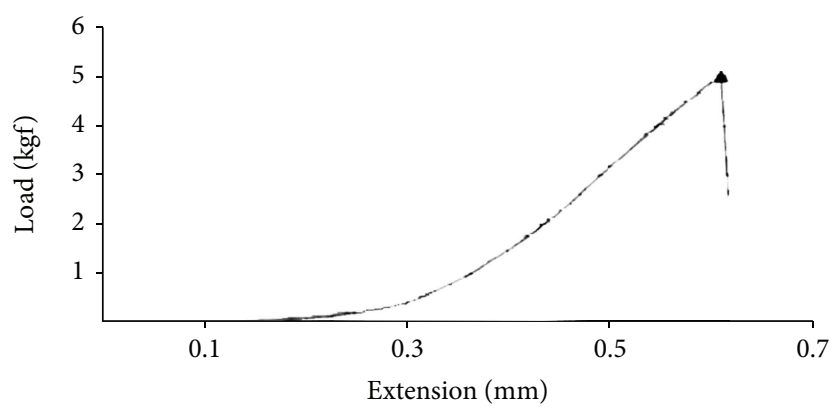

(f)

Figure 2: Typical behavior of films under tension tests: (a) MBO; (b) PVA/CG film; (c) PVA/CG-AG film; (d) PVA/AG $\mathrm{PO}_{4}$ film; (e) PVA/AG HCl film; and (f) PVA/AG ac film.

The behavior of the films under tension test is depicted in Figure 2. Analyzing the behavior of the $\mathrm{MBO}$ under tension test (Figure 2(a)), it is possible to observe three zones-the first characterized by an increase in the load accompanied by extension of the film, followed by a zone in which the extension occurs without increases in the load and the point of rupture of the film. As can be seen, the extension of $\mathrm{MBO}$ film occurred at a maximum load of $3.65 \mathrm{kgf}$. Similar behavior was observed for PVA/CG film (Figure 2(b)) although the maximum load to extend the film has been $2.49 \mathrm{kgf}$.

Regarding PVA/AG (Figures 2(d) and 2(e)) or PVA/AG films (Figure 2(f)), the tension test showed an absence of an elastic zone. It seems that the acid used as a catalyst may influence the load necessary to extend the film. The $\mathrm{PVA} / \mathrm{AG}_{\mathrm{ac}}$ film required the highest load to rupture (5.0 kgf).

The films produced by blending PVA/CG-AG presented the best set of features regarding the properties of strength and flexibility (Figure 2(c)).
The different behavior observed for the blended films may be ascribed to the chemical structure of the polysaccharides. The property of starches to produce film is related to the relative amount of amylose and amylopectin present in the starch granule. The branching degree and the relative amount of amylopectin present in the starch granule will determine the elastic property of the produced film [14]. In this sense, the different behavior of the blended films may be ascribed to different branching degree or the higher molar mass of AG $\left(3.7 \times 10^{6} \mathrm{~g} \mathrm{~mol}^{-1}\right)$ compared to CG $\left(6.41 \times 10^{4} \mathrm{~g} \mathrm{~mol}^{-1}\right)[7,15]$.

The mechanical characteristics of PVA blended films are shown in Table 1. The tensile strength (TS) is defined as the capacity of resistance to rupture presented by the material when submitted to pressure force [16]. On the other hand, the percentage of elongation $(E \%)$ is related to the elasticity of a material since it is measured through the extension under traction. The blended films showed TS and $E \%$ quite diverse. 


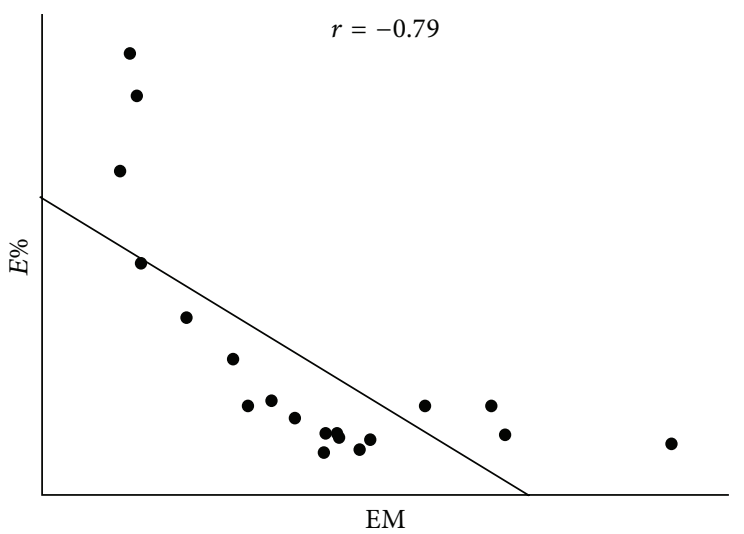

(a)

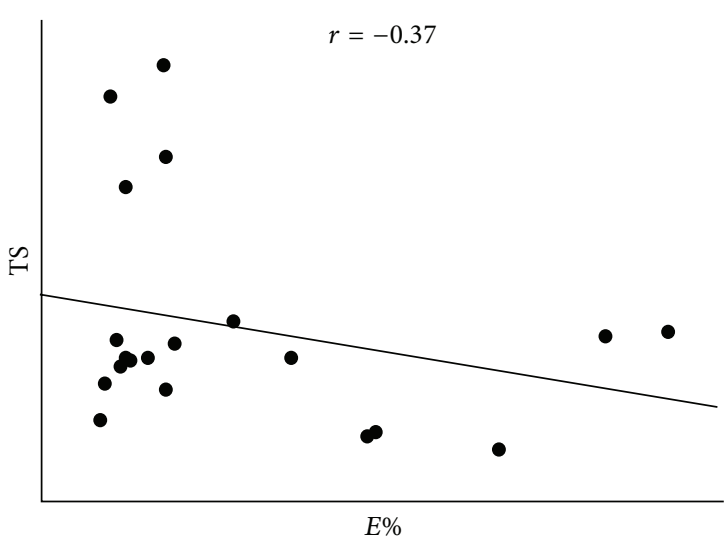

(b)

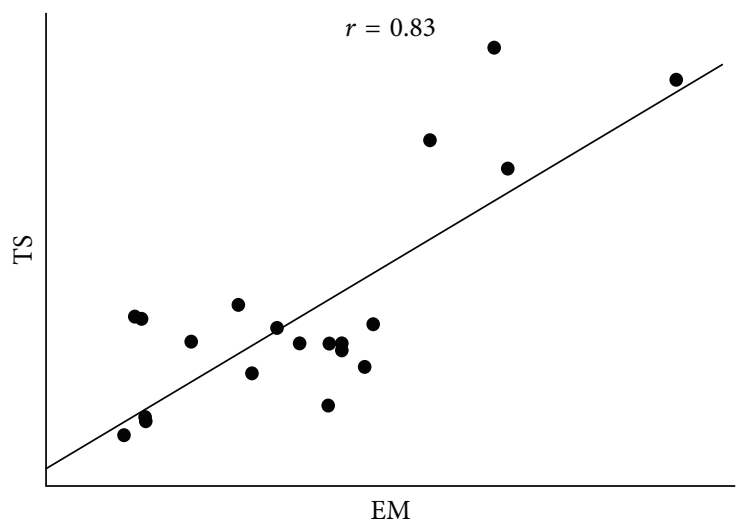

(c)

Figure 3: Graphic representation of Pearson's correlation between (a) percentage of elongation (E\%) and elastic modulus (EM), (b) tensile strength (TS) and percentage of elongation (E\%), and (c) tensile strength (TS) and elastic modulus (EM).

The film that presented the higher TS was $\mathrm{PVA} / \mathrm{AG}_{\mathrm{HCl}}$ with a value twofold higher than $\mathrm{MBO}$. However, the value of $E \%$ of $\mathrm{PVA} / \mathrm{AG}_{\mathrm{HCl}}$ did not differ from that of MBO. From these results, it is possible to infer that the polymers chains in the blended film are tightly bounded, with a very low degree of flexibility.

On the other hand, the PVA/CG film showed a remarkable percentage of elongation (E\%), fourfold higher than $\mathrm{MBO}$. It seems that the polymers chains of the blended film, although covalently bounded, preserved a certain degree of chain flexibility.

Regarding the elastic modulus (EM), three groups with distinct properties were observed: (i) $\mathrm{PVA} / \mathrm{AG}_{\mathrm{HCl}}$ with the highest value of $\mathrm{EM}$; (ii) $\mathrm{MBO}, \mathrm{PVA} / \mathrm{AG}_{\mathrm{PO}_{4}}$, and $\mathrm{PVA} / \mathrm{AG}_{\mathrm{ac}}$ with EM around 6900-4700 kgf; and (iii) PVA/CG and PVA/CG-AG, with values of EM around $1300-1800 \mathrm{kgf}$ (Table 1).

The results of the correlation analysis evidenced a positive relationship between TS and EM $(r=0.84)$, whereas the $E \%$ had a negative correlation with EM $(r=-0.79)$. This observation is evidenced in Figure 3.

Considering the macroscopic features and the mechanical properties of the blended films, the PVA/CG showed characteristics that enable this material to substitute the
MBO with the advantage of higher $E \%$. Furthermore, the composition of PVA/CG is advantageous regarding the safety of the material used, since it uses a plant polysaccharide instead of an animal protein.

Although the films produced with angico gum presented inferior macroscopic characteristics, the $\mathrm{PVA} / \mathrm{AG}_{\mathrm{HCl}}$ film showed remarkable mechanical properties such as the high values of TS and EM. In this sense, this material is also promising for biotechnological applications.

\section{Conclusion}

The films produced by blending PVA with AG and/or CG presented quite different macroscopic and mechanical properties. Among them, the PVA/CG film presented the macroscopic and mechanical properties similar to $\mathrm{MBO}$ film, with the advantage of a higher $E \%$ (11.96) than $\mathrm{MBO}$ (2.94). On the other hand, the $\mathrm{PVA} / \mathrm{AG}_{\mathrm{HCl}}$ presented higher values of TS and EM. The inclusion of CG in the blend PVA/AG-CG improved the $E \%$ of this film, compared to the other PVA/AG films. Finally, all produced films presented interesting mechanical characteristics, which enables several biotechnological applications. 


\section{Conflict of Interests}

The authors do not have any conflict of interests with the content of the paper.

\section{Acknowledgment}

F. E. F. Silva, M. C. B. Di-Medeiros, and K. A. Batista thank CAPES for the fellowship support.

\section{References}

[1] K. G. Satyanarayana, G. G. C. Arizaga, and F. Wypych, "Biodegradable composites based on lignocellulosic fibers-an overview," Progress in Polymer Science, vol. 34, no. 9, pp. 9821021, 2009.

[2] K. Y. Lee and D. J. Mooney, "Alginate: properties abd biomedical applications," Progress in Polymer Science, vol. 37, pp. 106-126, 2012.

[3] E. Khor, H. Wu, L. Y. Lim, and C. M. Guo, "Chitin-methacrylate: preparation, characterization and hydrogel formation," Materials, vol. 4, pp. 1728-1746, 2011.

[4] S. Tripathi, G. K. Mehrotra, and P. K. Dutta, "Physicochemical and bioactivity of cross-linked chitosan-PVA film for food packaging applications," International Journal of Biological Macromolecules, vol. 45, no. 4, pp. 372-376, 2009.

[5] E. S. Costa-Júnior, E. F. Barbosa-Stancioli, A. A. P. Mansur, W. L. Vasconcelos, and H. S. Mansur, "Preparation and characterization of chitosan/poly(vinyl alcohol) chemically crosslinked blends for biomedical applications," Carbohydrate Polymers, vol. 76, no. 3, pp. 472-481, 2009.

[6] I. S. Fahim, S. M. Elhaggar, and H. Elayat, "Experimental investigation of natural fiber reinforced polymers," Materials Sciences and Applications, vol. 3, pp. 59-66, 2012.

[7] M. A. Oliveira, D. A. Silva, D. E. A. Uchoa et al., "Synthesis and characterization of carboxymethylated red angico (Anadenanthera macrocarpa) exudate polysaccharide," Journal of Applied Polymer Science, vol. 103, no. 5, pp. 2985-2991, 2007.

[8] R. C. M. De Paula, P. M. Budd, and J. F. Rodrigues, "Characterization of Anadenanthera macrocarpa exudate polysaccharide," Polymer International, vol. 44, no. 1, pp. 55-60, 1997.

[9] T. M. Silva, P. O. Santiago, L. L. A. Purcena, and K. F. Fernandes, "Study of the cashew gum polysaccharide for the horseradish peroxidase immobilization-structural characteristics, stability and recovery," Materials Science and Engineering C, vol. 30, no. 4, pp. 526-530, 2010.

[10] J. S. Maciel, D. A. Silva, H. C. B. Paula, and R. C. M. De Paula, "Chitosan/carboxymethyl cashew gum polyelectrolyte complex: synthesis and thermal stability," European Polymer Journal, vol. 41, no. 11, pp. 2726-2733, 2005.

[11] D. M. W. Anderson and P. C. Bell, "Structural analysis of the gum polysaccharide from anacardium occidentale," Analytica Chimica Acta, vol. 79, no. C, pp. 185-197, 1975.

[12] ASTM, "Designation: D638M-93, standard test method for tensile properties of thin plastic sheeting," in Annual Book of ASTM Standards, ASTM, Philadelphia, Pa, USA, 1995.

[13] D. F. Stamatialis, B. J. Papenburg, M. Gironés et al., "Medical applications of membranes: drug delivery, artificial organs and tissue engineering," Journal of Membrane Science, vol. 308, no. 1-2, pp. 1-34, 2008.
[14] Y. U. Nabar, D. Draybuck, and R. Narayan, "Physicomechanical and hydrophobic properties of starch foams extruded with different biodegradable polymers," Journal of Applied Polymer Science, vol. 102, no. 1, pp. 58-68, 2006.

[15] S. Bose and M. Biswas, "The structure of the gum of Anacardium occidentale," Acta Horticulturae, vol. 108, pp. 207-217, 1985.

[16] F. Yamashita, A. Nakagawa, G. F. Veiga, S. Mali, and M. V. E. Grossmann, "Biodegradable active packaging for minimally processed fruits and vegetables," Brazilian Journal of Food Technology, vol. 8, pp. 335-343, 2005. 

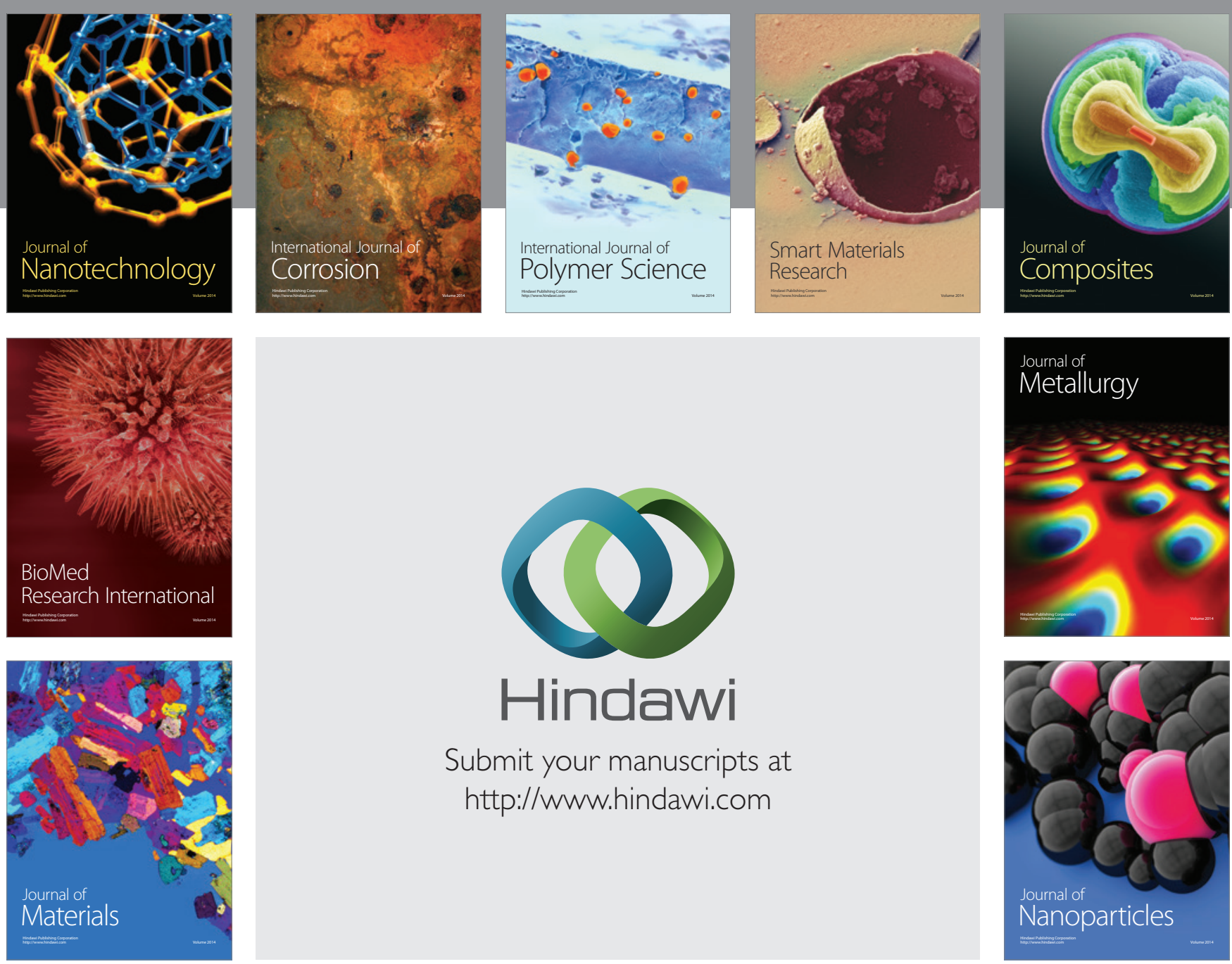

Submit your manuscripts at http://www.hindawi.com
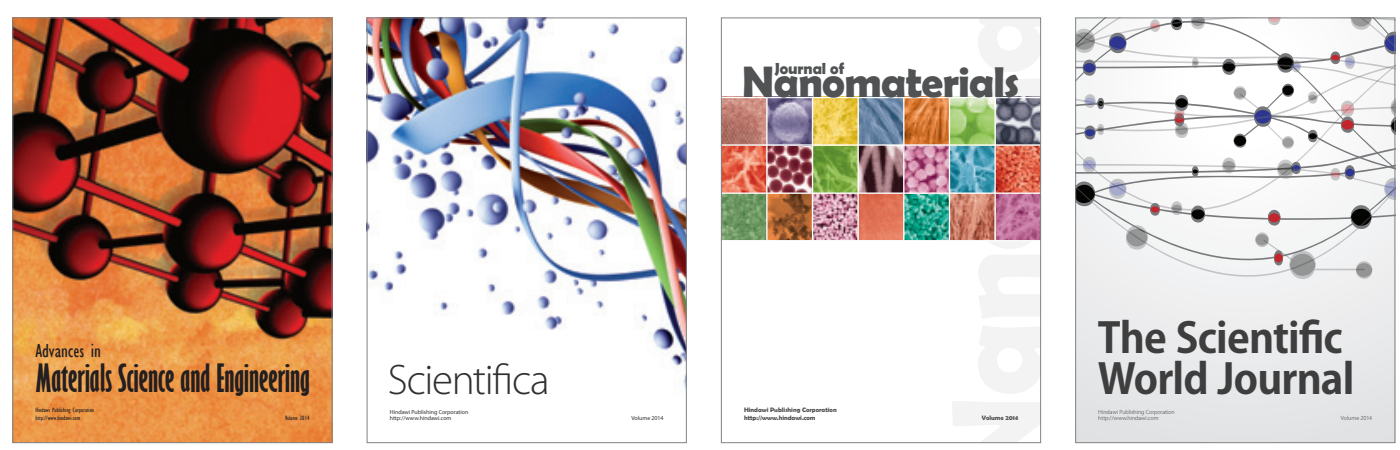

\section{The Scientific World Journal}
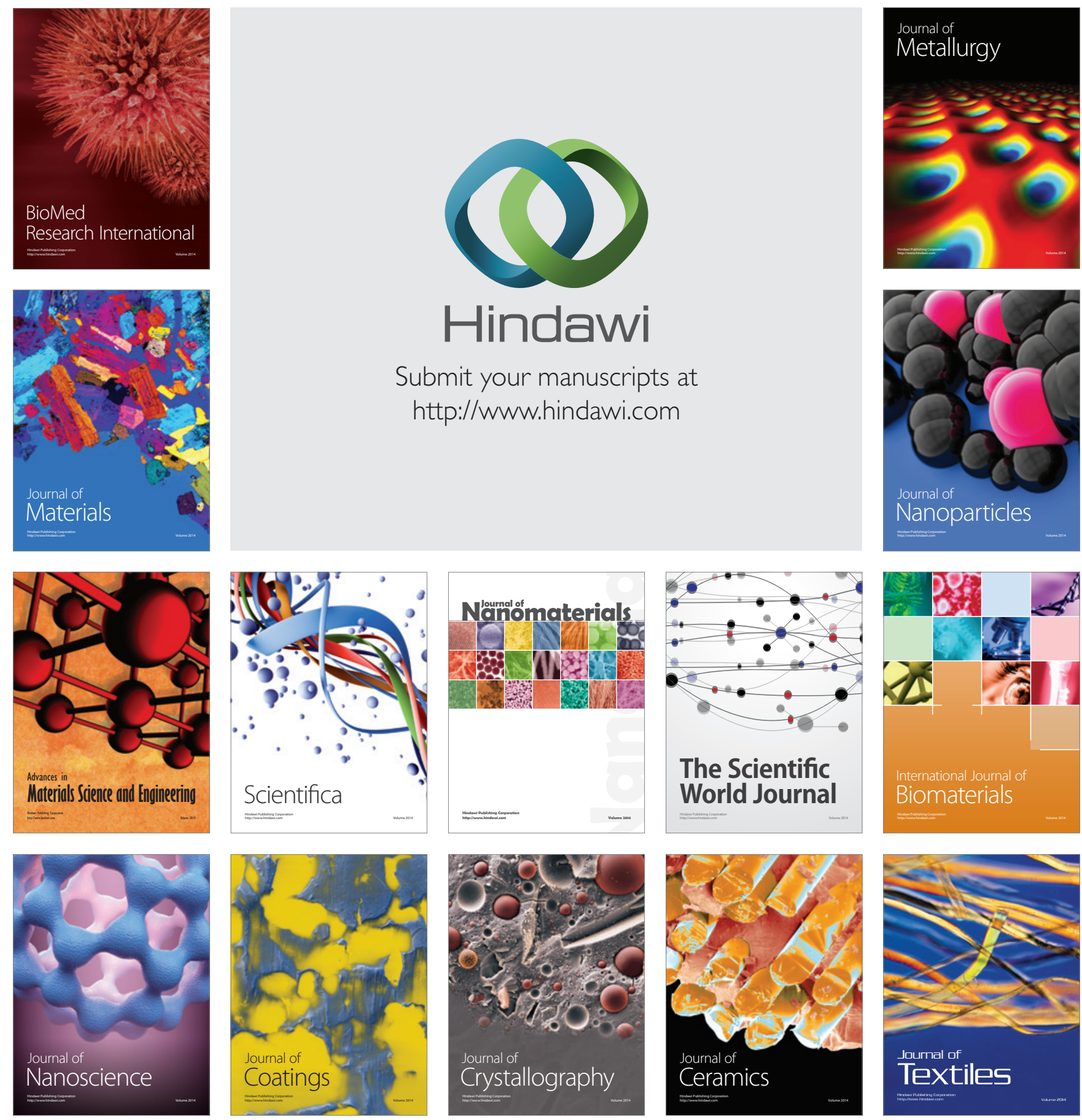